\title{
Public Health Risk Assessment of the Door Handles of the Community Pharmacies in Qassim Region, Saudi Arabia
}

\author{
Raya Alothaim ${ }^{1}$ (D) Ahmad Almatroudi ${ }^{2}$, Monir Uddin Ahmed ${ }^{2}$ (D), \\ Masood Alam Khan ${ }^{3}$ (D), Rejo Jacob Joseph ${ }^{3}$ (D) , Abdullah Alharbi ${ }^{4}$ (D), \\ Mohammed Alkathlan ${ }^{5}$ id and Khaled S. Allemailem ${ }^{2,3, *}$ (D)
${ }^{1}$ Department of Pharmacy Practice, College of Pharmacy, Qassim University, Buraydah, Saudi Arabia.
${ }^{2}$ Department of Medical Laboratories, College of Applied Medical Sciences, Qassim University, Buraydah, Saudi Arabia.
${ }^{3}$ Department of Basic Health Sciences, College of Applied Medical Sciences, Qassim University, Buraydah Saudi Arabia.
${ }^{4}$ Department of Microbiology, Bukayriah Hospital, Bukayriah, Saudi Arabia.
${ }^{5}$ Department of Medicine, King Fahad Specialist Hospital, Buraydah, Saudi Arabia.

\begin{abstract}
Door handles are being reported to harbor a diverse group of microorganisms, mainly bacteria. Presence of pathogenic and antibiotic-resistant bacteria in the door handles carry risk to the health of the public. For this reason, a study was carried in the Qassim region of Saudi Arabia by isolating bacteria from the pharmacy door handles from four different areas. Total 100 samples were collected by wiping the door handles with a sterile cotton swab soaked in sterile water. Microorganisms were isolated using Blood agar and MacConkey agar and identified following standard microbiological procedure. Siemens MicroScan Walkaway system was used for determination of antibiotic susceptibility pattern. In total, 301 bacteria from 13 bacterial species were isolated and identified. The predominant bacterial species include Staphylococcus spp. $56.48 \%$ followed by Bacillus spp. $12.29 \%$ and Micrococcus spp. $\mathbf{1 0 . 3 0 \% .}$ Gram-negative bacteria like Shigella sonnei and Salmonella paratyphiA were also isolated. Being the most predominant species, Antibiotic resistance pattern of 39 Staphylococcus spp. were determined. $38.46 \%$ of the Staphylococcus spp. were found to be resistant to Cefoxitin, and $\mathbf{3 0 . 7 6 \%}$ were betalactamase producing. The results also indicated that about one -third of Staphylococcus spp. were methicillin resistant. The door handles of pharmacies in the Qassim region carry risk to the health of the public. Proper hygienic measures are recommended for the public health safety until doors are made automatic and touch-free.
\end{abstract}

Keywords: Bacillus, $\beta$-lactamase, Cefoxitin, door handle, Micrococcus, pharmacy, public health, risk, Saudi Arabia, Staphylococcus

(C) The Author(s) 2020. Open Access. This article is distributed under the terms of the Creative Commons Attribution 4.0 International License which permits unrestricted use, sharing, distribution, and reproduction in any medium, provided you give appropriate credit to the original author(s) and the source, provide a link to the Creative Commons license, and indicate if changes were made. 


\section{INTRODUCTION}

The transfer efficiency of microbes to the hands is higher from hard and nonporous surfaces such as acrylic, glass, ceramic tile, laminate, stainless steel, and granite as compared to the transfer from porous surfaces ${ }^{1}$. The door handles of community pharmacies are usually made of nonporous surfaces, which raises the chance of possible transmission of potentially pathogenic and multi-drug resistant (MDR) bacteria in the community. Door's location, design and mode of use influence the degree of handle colonization ${ }^{2}$.

The risk of bacterial transmission to the hands is proportional to its duration of survival on the handle, which depends on the environmental factors like temperature and humidity, the presence of organic matter on the handle, the ability of bacteria to form the biofilms and standard cleaning practices ${ }^{3}$. Factors like the frequency of site contamination, the level of pathogen excreted by the host, the virulence of the bacteria and immune status of a person in contact determine the risk of disease transmission from the contaminated handle. However, the contribution of such microbial transfer to the transmission of diseases is unclear 4 .

Bacteria like Enterococcus spp. (including VRE), Staphylococcus aureus (including MRSA), Streptococcus pyogenes, Acinetobacter spp., Escherichia coli, Klebsiella spp., Shigella spp, can survive on the dry surfaces for months ${ }^{5}$. Some bacteria can only survive for days like Haemophilus influenzae and Proteus Vulgaris. The difference in the survival between multi-drug resistant and susceptible strains of Staphylococcus aureus and Enterococcus spp. is not significant. Gram-negative bacteria had longer survival than gram-positive bacteria ${ }^{5}$.

Earlier studies showed the most commonly identified bacteria colonized the door handles in public bathrooms include Staphylococcus aureus, S. epidermidis, Proteus spp., Klebsiella, Enterobacter, Acinetobacter spp., and Gut normal flora such as Enterococcus faecalis, Escherichia coli and Enterobacter ${ }^{6}$.

In Saudi Arabia, the community pharmacies have closed glass doors with steel handles, and people need to hold/touch the handles to get in and out of the pharmacy. So, the pharmacy door handles, touched by people from all walk of life, can be a source of transmission of pathogens among people.

The present study was aimed to assess the public health risk from the pharmacy door handles by isolating and identifying the bacterial species and evaluating their antibacterial susceptibility patterns in Qassim region of Saudi Arabia.

\section{MATERIALS AND METHODS}

This study was carried between February 2019 and April 2019, in the Department of Medical Laboratories, College of Applied Medical Sciences, Qassim University, Buraydah, Saudi Arabia.

\section{Sample collection}

Samples were collected from door handles of pharmacies from three different cities and countryside in Qassim: Buraydah, Unaizah, Alrass and countryside of Qassim. Twenty-five sets of samples were collected from each city. In total, 100 samples were collected by wiping the door handles with a sterile cotton swab soaked in sterile water.

\section{Culturing}

The samples were cultured by streaking onto Blood agar and MacConkey agar; incubated at $37^{\circ} \mathrm{C}$ for 24 hours.

\section{Preliminary identification of bacterial isolates}

Bacterial isolates were identified by both macroscopic examination of the colony characteristics including color, size, the elevation of margin and surface texture, and microscopic characteristics of bacterial cell such as morphology and arrangements visualized by gram staining and microscopy as well as on their ability to ferment lactose on MacConkey and hemolyze blood on blood agar.

\section{Motility test}

The hanging drop method was used for further identification of the Gram-negative rods ${ }^{7}$.

\section{Biochemical tests}

API20 was carried out according to the manufacturer instructions (Biomeriux, France).

\section{Confirmatory identification}

MicroScan Walkaway System was used to confirm the identification of the isolated bacteria ${ }^{8}$. Determination of antimicrobial susceptibility pattern

For the isolated strains, antibacterial susceptibility patterns were tested using MicroScan Walkaway system ${ }^{8}$. Cefoxitin screening was carried 
out by disc diffusion method ${ }^{9}$, and $\beta$-lactamase production was assayed following the modified Perret's iodometricassay ${ }^{10}$.

\section{RESULTS}

One hundred pharmacy's door handles were sampled in total from four different areas. All 100 door handles from all pharmacies were found to be colonized with various types of bacteria. Three hundred and one ( $\mathrm{N}=301)$ bacteria were isolated, which belong to 13 different species. The name of the species and their abundance is shown in (Table 1). Three dominant spp. were Staphylococcus spp. $56.48 \%$ followed by Bacillus spp. $12.29 \%$ and Micrococcus spp. $10.30 \%$. Gram-negative bacteria like Shigella sonnei and Salmonella paratyphi A were also isolated (Table 1).

\section{City distribution of contaminations}

Pharmacy door handles from all four regions were almost equally contaminated with bacteria. There were no significant differences in the number of isolated bacteria from different regions. Among the 301 bacteria, the highest number of bacteria $26.25 \%$ were isolated from 25 door handles in Buraydah, and the lowest number of bacteria $23 \%$ were isolated from 25 door handles in Alrass (Fig. 1).

Table 1. Isolated bacterial Species $(\mathrm{N}=13)$ and their relative abundance (\%)

\begin{tabular}{lcc}
\hline Name of the Species & $\mathrm{N}$ & $\%$ \\
\hline 1. Staphylococcus spp. & 170 & 56.48 \\
2. Bacillus spp. & 37 & 12.30 \\
3. Micrococcus spp. & 31 & 10.30 \\
4. Panatoea spp. & 21 & 6.98 \\
5. Acinetobacter spp. & 19 & 6.31 \\
6. Enterococcus faecalis & 7 & 2.33 \\
7. Enterobacter spp. & 4 & 1.33 \\
8. Shigella sonnei & 3 & 1.00 \\
9. Serratia plymuthica & 2 & 0.66 \\
10. Weeksella virosa & 2 & 0.66 \\
11. Klebsiella rhinoscleromatis & 2 & 0.66 \\
12. Rhizobium radiobacter & 2 & 0.66 \\
13. Salmonella paratyphi A & 1 & 0.33 \\
Total & 301 & 100 \\
\hline
\end{tabular}

\section{Antibiotic resistance pattern of the isolated staphylococcal spp.}

Staphylococcal spp. were the most prevalent $56 \%$, (Table 1) among the bacterial spp. found in the door handles of pharmacies in Qassim region. Moreover, Staphylococcus spp. is the most significant among the isolated bacteria as a pathogen. Hence, Multi-drug resistance pattern of Staphylococcus spp. was determined by using 19 different antibiotics. In addition to that, cefoxitin resistance pattern and beta-lactamase production ability of the staphylococcal spp. were determined (Table 2).

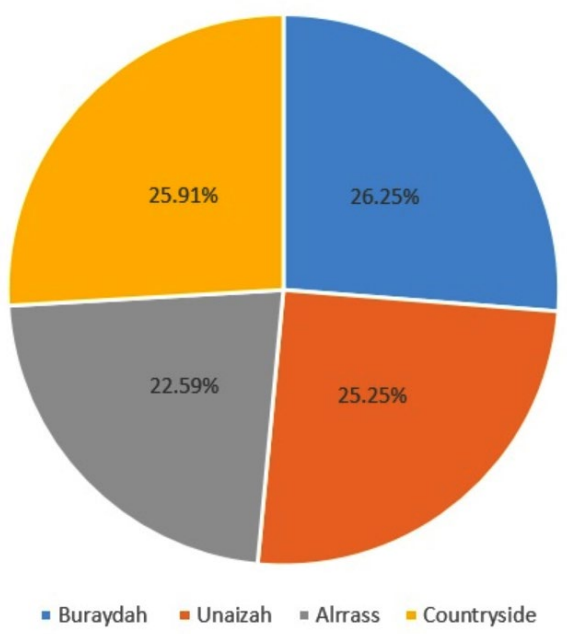

Fig. 1. City distribution of bacterial contamination in Qassim region

Table 2. Cefoxitin test and beta lactamases for Staphylococcus spp. ( $\mathrm{N}=39)$

\begin{tabular}{lccccc}
\hline & \multicolumn{2}{c}{ Cefoxitin screen test } & \multicolumn{2}{c}{ Beta lactamase } \\
\cline { 2 - 3 } & \multicolumn{2}{c}{ Positive } & & \multicolumn{2}{c}{ Positive } \\
\cline { 2 - 3 } \cline { 5 - 6 } & $\mathrm{N}$ & $\%$ & & $\mathrm{~N}$ & $\%$ \\
\hline S. aureus & 0 & 0 & & 5.12 \\
S.haemolyticus & 5 & 12.82 & & 0 \\
S.auricularis & 0 & 0 & & 0 \\
S.capitis & 1 & 2.56 & & 2.56 \\
S.hominis & 6 & 15.40 & 2 & 5.12 \\
S.epidermidis & 1 & 2.56 & 3 & 7.70 \\
S.stimulans & 1 & 2.56 & 0 & 0 \\
S.warneri & 0 & 0 & 3 & 7.70 \\
S.sciuri & 0 & 0 & 0 & 0 \\
S.hyicus & 1 & 2.56 & 0 & 0 \\
Total & 15 & 38.46 & 12 & 30.76 \\
& \multicolumn{5}{c}{ www.microbiologyjournal.org }
\end{tabular}


Among the (N=39) Staphylococcus spp., 92.31\% showed antibiotic resistance (Fig. 2). Antibiotic resistance pattern of 10 Staphylococcus spp. was determined by using 19 antibiotics. S. epidermidis, S. haemolyticus, S. hominis, $S$. auricularis were found to be resistant to antibiotics from more than three different groups. Thus, they are multi-drug resistant. Among 39 Staphylococcus spp., $38.46 \%$ of the Staphylococcus spp. were found to be resistant to Cefoxitin, and $30.76 \%$ were beta-lactamase-producing (Table 2). This means that about one -third of Staphylococcus spp. were methicillin-resistant.

\section{Antibiotic susceptibility pattern of gram-negative bacteria}

Thirty-seven ( $N=37$ ) Gram-negative bacteria were also evaluated for antibiotic susceptibility, $21.62 \%$ and $13.51 \%$ were resistant and intermediate resistant, respectively (Fig. 3). Three $S$. sonnei strains $(\mathrm{N}=3)$ were isolated from two different locations; two were evaluated for antibiotic susceptibility. Both had intermediate resistance to Ampicillin with minimum inhibitory concentration (MIC) of $16 \mu \mathrm{g} / \mathrm{mL}$.

\section{DISCUSSION}

This is the first study conducted on pharmacy door handles in Saudi Arabia for microbial contamination. This study found that all the pharmacy door handles from all three towns and countryside were contaminated. There is a negligible difference in colonization rate between the four locations (Fig. 1).

The results also revealed that pharmacy door handles were colonized with a diverse group of bacterial species. Most of the isolated species $81.41 \%$ were gram-positive, whereas $18.59 \%$ were found to be gram-negative. Among the gram-positive bacteria, three major species are Staphylococcus, Micrococcus and Bacillus. All these three species are found in soil, air and water, nose, and skin. From these sources and places, these bacteria usually can find their destination to hands and then to door handles and found in the door handles of pharmacy. Staphylococcus and Bacillus cause disease and Micrococcus is an opportunistic pathogen ${ }^{11,12}$. Thus, their presence in the pharmacy door handles is a threat to the health of the people coming to the pharmacy for buying medicine.

Pathogenic gram-negative bacteria like Shigella sonnei and Salmonella paratyphi A were reported in this study. Salmonella spread through the feco-oral route, it is usually transmitted by food and water, and rarely from person to person. The risk of infection increases in immunocompromised

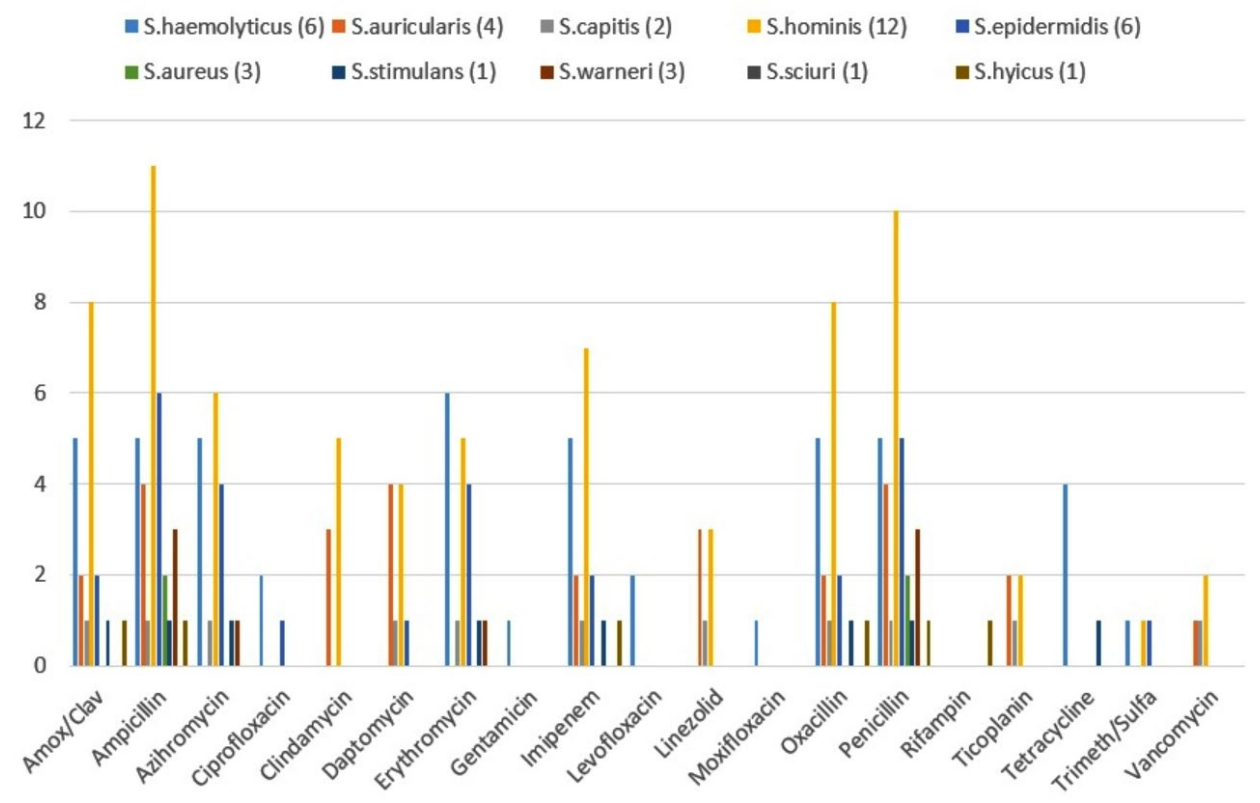

Fig. 2. Antibiotic susceptibility pattern of gram-positive bacteria 


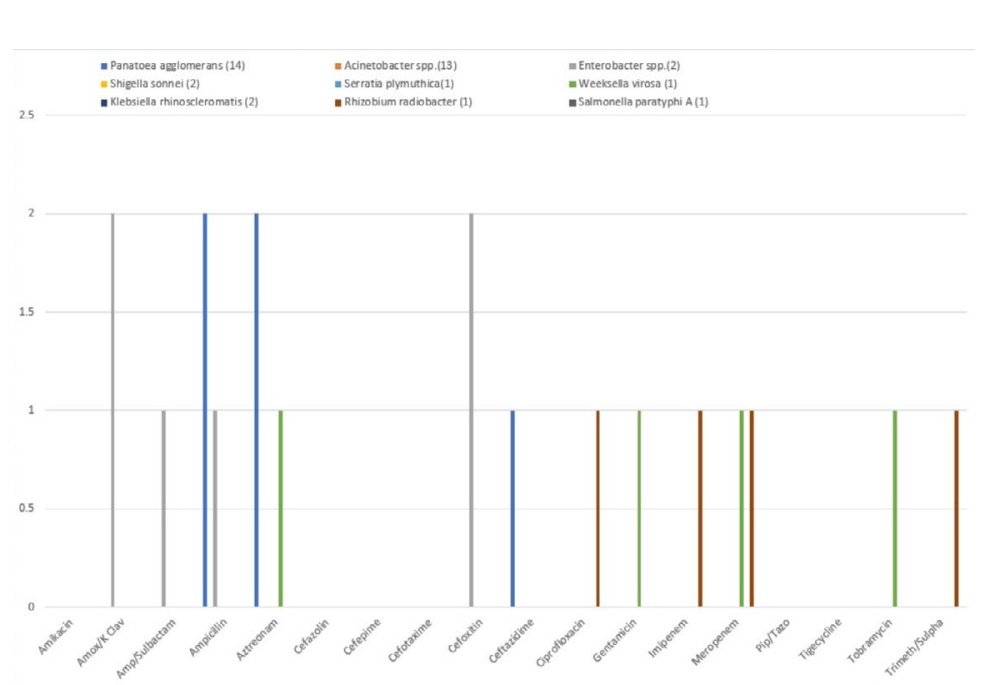

Fig. 3. Antibiotic susceptibility pattern of gram-negative bacteria

persons. Three Salmonella paratyphi A were identified, two of which were isolated from pharmacies near to a clinic. The first case of Rhizobium radiobacter was published in 1980 as a case of prosthetic valve endocarditis ${ }^{13}$. It is a motile, aerobic, gram-negative plant pathogen that is usually found in soil. Most of the reported cases in humans are in immunocompromised situations with central venous catheters ${ }^{14}$. In this study, two Rhizobium radiobacter were identified. One was isolated from a pharmacy door handle next to a plant nursery in Alrass, the other from Unaizah main street (Table 1). All these results of the present study agreed with previous studies indicating the possibility of contamination of solids, such as handles of home doors and office doors, with opportunistic and pathogenic bacteria $^{15,16}$.

Staphylococcus spp. were the most abundant bacterial spp. Among the bacteria found in the samples, and they showed antibiotic resistance to several antibiotics (Fig. 2). This finding is like the findings of many other studies which found multi-drug resistant Staphylococcus in the door handles of different settings, such as hospitals ${ }^{17,18}$.

One-third of the Staphylococcal isolates were found methicillin-resistant. These findings are also supported by previous studies elsewhere ${ }^{12,19,20}$. Gram-negative isolates showed higher resistance to Ampicillin and Aztreonam, followed by Amoxicillin/clavulanate, Cefoxitin and Meropenem.

This study demonstrated that pharmacies door handles were colonized with pathogenic and multi-drug resistance bacteria, which can act as a potential source of direct bacterial transmission to the community. Community awareness on the hand hygiene should be raised, and the efficacy of standard cleaning of the door handles should be revised. The use of automatic doors is highly recommended to reduce crosscontamination. Further studies on the biofilm formation, production of enterotoxin and regular surveillance are recommended to monitor public health risk from pharmacy door handles.

\section{CONCLUSION}

A diverse group of bacteria colonizes all the door handles. Staphylococcus, Micrococcus and Bacillus are the three predominant spp. of bacteria found in the door handles of pharmacy in the Qassim region. The bacteria are resistant to a significant number of antibiotics, and one-third of them are methicillin-resistant as revealed by cefoxitin test and beta-lactamase production. Thus, the door handles of pharmacy in this region pose a threat to public health. Proper hygienic measures should be taken until doors are made automatic so that people do not need to touch or hold the door handles. 


\section{ACKNOWLEDGMENTS}

None.

\section{CONFLICT OF INTEREST}

The listed author(s) declare that there is no conflict of interest.

\section{AUTHORS' CONTRIBUTION}

All listed author(s) have made a substantial, direct and intellectual contribution to the work, and approved it for publication.

\section{FUNDING}

None.

\section{DATA AVAILABILITY}

All datasets generated or analyzed during this study are included in the manuscript.

\section{ETHICS STATEMENT}

This article does not contain any studies with human participants or animals performed by any of the authors.

\section{REFERENCES}

1. Lopez GU, Gerba CP, Tamimi AH, Kitajima M, Maxwell $\mathrm{SL}$, Rose JB. Transfer efficiency of bacteria and viruses from porous and nonporous fomites to fingers under different relative humidity conditions. Appl Environ Microbiol. 2013;79(18):5728-5734. doi: 10.1128/ AEM.01030-13

2. Wojgani H, Kehsa C, Cloutman-Green E, Gray C, Gant $\mathrm{V}$, Klein N. Hospital door handle design and their contamination with bacteria: a real life observational study. Are we pulling against closed doors? PLOS ONE. 2012;7(10):e40171. doi: 10.1371/journal. pone.0040171

3. Bhatta DR, Hamal D, Shrestha R, et al. Bacterial contamination of frequently touched objects in a tertiary care hospital of Pokhara, Nepal: how safe are our hands? Antimicrob Resist Infect Control. 2018;7:97. doi: 10.1186/s13756-018-0385-2

4. Bright KR, Boone SA, Gerba CP. The occurrence of bacteria and viruses on elementary classroom surfaces and the potential role of classroom hygiene in the spread of infectious diseases. J Sch Nurs. 2010;26(1):33-41. doi: 10.1177/1059840509354383

5. Kramer A, Schwebke I, Kampf G. How long do nosocomial pathogens persist on inanimate surfaces? A systematic review. BMC Infect Dis. 2006;6,130. doi: 10.1186/1471-2334-6-130

6. Plotkin GR. Agrobacterium radiobacter prosthetic valve endocarditis. Ann Intern Med. 1980;93(6):839-840. doi: 10.7326/0003-4819-93-6-839

7. Wauters G, Vaneechoutte M. Approaches to the Identification of Aerobic Gram-Negative Bacteria.
Manual of Clinical Microbiology, Eleventh Edition: American Society of Microbiology. 2015. doi: 10.1128/9781555817381.ch33

8. McGregor A, Schio F, Beaton S, Boulton V, Perman M, Gilbert G. The MicroScan Walk Away diagnostic microbiology system - an evaluation. Pathol. 1995;27(2):172-176. doi: $10.1080 / 00313029500169822$

9. NCCLS. Performance Standards for Antimicrobial Disk Susceptibility Tests. Eighth Edition; Approved Standard M2-A8Wayne, PA, USA. 2003.

10. Workman RG, Farrar WE, Jr. Activity of penicillinase in Staphylococcus aureus as studied by the iodometric method. J Infect Dis. 1970;121(4):433-437. doi: 10.1093/infdis/121.4.433

11. Cote CK, Heffron JD, Bozue JA, Welkos SL. Chapter 102 - Bacillus anthracis and Other Bacillus Species. In: Tang Y-W, Sussman M, Liu D, Poxton I, Schwartzman J, editors. Molecular Medical Microbiology (Second Edition). Boston: Academic Pres.; 2015:1789-1844. doi: 10.1016/B978-0-12-397169-2.00102-5

12. Foster TJ. Antibiotic resistance in Staphylococcus aureus. Current status and future prospects. FEMS Microbiol Rev. 2017;41(3):430-449. doi: 10.1093/ femsre/fux007

13. Gruszecki AC, Armstrong SH, Waites KB. Rhizobium radiobacter bacteremia and its detection in the clinical laboratory. Clin Microbiol Newsl. 2002;24(20):151-155. doi: 10.1016/S0196-4399(02)80038-1

14. Chen $\mathrm{CY}$, Hansen KS, Hansen LK. Rhizobium radiobacter as an opportunistic pathogen in central venous catheter-associated bloodstream infection: case report and review. J Hosp Infect. 2008;68(3):203-207. doi: 10.1016/j.jhin.2007.11.021

15. Nworie A, AyeniJ A. Bacterial contamination of door handles/knobs in selected public conveniences in Abuja metropolis, Nigeria: A public health threat. $C J$ Med Res. 2012;6(1):7-11.

16. Onwubiko NE, Helen Chinyeaka A. Isolation and identification of bacterial contaminants from door handles in a tertiary institution in Umuahia, Abia State, Nigeria. NJM. 2015;29:3139-3147.

17. Saba CKS, Amenyona JK, Kpordze SW. Prevalence and pattern of antibiotic resistance of Staphylococcus aureus isolated from door handles and other points of contact in public hospitals in Ghana. Antimicrob Resist Infect Control. 2017;6:44. doi: 10.1186/s13756-0170203-2

18. Fakhoury S, Nwas T. Contamination of the internal handles/knobs of public restroom doors with potentially pathogenic bacteria. Int J Curr Microbiol Appl Sci. 2018;7:3434-3440. doi: 10.20546/ ijcmas.2018.703.395

19. Otarigho B, Falade MO. Analysis of antibiotics resistant genes in different strains of Staphylococcus aureus. Bioinformation. 2018;14(3):113-122. doi: 10.6026/97320630014113

20. Robles BF, Nobrega DB, Guimaraes FF, Wanderley GG, Langoni H. Beta-lactamase detection in Staphylococcus aureus and coagulase-negative Staphylococcus isolated from bovine mastitis. Pesq Vet Bras. 2014;34:325-328. doi: 10.1590/S0100-736X2014000400004 